\title{
Decreased ribosomal DNA transcription in dorsal raphe nucleus neurons differentiates between suicidal and non-suicidal death
}

\author{
Marta Krzyżanowska $^{1} \cdot$ Johann Steiner $^{2} \cdot$ Karol Karnecki $^{1} \cdot$ Michał Kaliszan $^{1}$ \\ Ralf Brisch $^{1} \cdot$ Marek Wiergowski $^{1} \cdot$ Katharina Braun $^{3} \cdot$ Zbigniew Jankowski $^{1}$. \\ Tomasz Gos ${ }^{1,2,3}$
}

Received: 13 August 2015 / Accepted: 12 November 2015 / Published online: 21 November 2015

(c) The Author(s) 2015. This article is published with open access at Springerlink.com

\begin{abstract}
An involvement of the central serotonergic system has been implicated in the pathogenesis of suicide. The dorsal raphe nucleus (DRN) is the main source of serotonergic innervation of forebrain limbic structures disturbed in suicidal behaviour. The study was carried out on paraffin-embedded brainstem blocks containing the DRN obtained from 27 suicide completers (predominantly violent) with unknown psychiatric diagnosis and 30 nonsuicidal controls. The transcriptional activity of ribosomal DNA (rDNA) in DRN neurons as a surrogate marker of protein biosynthesis was evaluated by the AgNOR silver staining method. Significant decreases in AgNOR parameters suggestive of attenuated rDNA activity were found in the cumulative analysis of all DRN subnuclei in suicide victims versus controls ( $U$ test $P$ values $<0.00001$ ). Our findings suggest that the decreased activity of rDNA transcription in DRN neurons plays an important role in suicide pathogenesis. The method accuracy represented by the area under receiver operating characteristic curve $(>80 \%)$
\end{abstract}

The authors dedicate this work to the memory of Professor Roman Hauser.

Electronic supplementary material The online version of this article (doi:10.1007/s00406-015-0655-4) contains supplementary material, which is available to authorized users.

Tomasz Gos

gost@gumed.edu.pl

1 Department of Forensic Medicine, Medical University of Gdańsk, ul. Dębowa 23, 80-204 Gdańsk, Poland

2 Department of Psychiatry, Otto-von-Guericke-University, Magdeburg, Germany

3 Department of Zoology/Developmental Neurobiology, Institute of Biology, Otto-von-Guericke-University, Magdeburg, Germany suggests a diagnostic value of the observed effect. However, the possible application of the method in forensic differentiation diagnostics between suicidal and non-suicidal death needs further research.

Keywords Post-mortem $\cdot$ Suicide $\cdot$ Dorsal raphe nucleus $\cdot$ AgNOR staining

\section{Introduction}

Disturbances of the central serotonergic system are implicated in a multifaceted way in suicidal behaviour (for reviews see: $[1,2]$ ), which has been proposed to be an independent mental disorder in the fifth edition of the Diagnostic and Statistical Manual of Mental Disorders-DSM V [3] in accordance with numerous neurobiological research data (for reviews see: [1,2]).

As revealed by neuropathological research on suicide, abnormalities in the serotonergic system may be structurally restricted to a specific brain region, the dorsal raphe nucleus (DRN), which affects brain circuits (for a review see: [4]). DRN neurons provide the major serotonergic innervation to the prefrontal cortex (PFC) [5-7], which plays a pivotal role in behavioural regulation. Limbic regions of the PFC (i.e. the anterior cingulate cortex and the orbitofrontal cortex) in turn may reciprocally regulate DRN function through direct pyramidal input $[8,9]$ modulated by serotonergic receptors in the PFC (for reviews see: [10-13]).

A number of post-mortem studies revealed changes in the DRN of suicide victims [14-28]. However, discrepancies resulting from various factors exist in the studies. Inconsistencies regarding psychiatric diagnosis, treatment, cause of death, the delineation of investigated areas, 
methodical issues and small sample sizes seem to be the most significant [29].

Nucleolar organising regions (NORs) are genetic loci on chromosomes that are composed of ribosomal DNA (rDNA) and proteins, some of which are argyrophilic. In human interphase cells, silver-stained NORs (AgNORs) clustered together in the nucleolus represent the site of transcriptionally active NORs and ribosomal RNA synthesis, which constitutes approximately one half of entire transcriptional activity in the cell. In the AgNOR staining evaluated by light microscopy, AgNORs are indistinguishable from each other and form the AgNOR area. They are located in the nucleolar area, but smaller than this area (compared, for instance, with haematoxylin-eosin and Nissl staining [30]). As a surrogate marker of protein biosynthesis and an important sensor of cellular stress of different nature, the transcriptional activity of rDNA can be assessed by measuring AgNOR parameters. These are: AgNOR area (representing the nucleolus), AgNOR number (i.e. the number of AgNOR areas within one nucleus) and AgNOR ratio defined as the quotient of total AgNOR area in the nucleus and nuclear area [18, 24, 31-42] (for reviews see: $[43,44])$.

A key role of rDNA transcriptional activity in neuronal plasticity has been proven in neuronal culture [45], and molecular studies have revealed that this activity is decreased in the suicidal hippocampus [46]. Our previous AgNOR studies of the DRN [24, 47] and other brain structures [33-37] in depression have suggested disturbed (predominantly decreased) rDNA transcription in neurons, specifically in suicidal patients, which is consistent with molecular results [46].

In the present study, we hypothesised a decreased rDNA transcriptional activity in DRN neurons in suicide completers regardless of their underlying psychiatric diagnosis (i.e. independent on psychiatric comorbidity) and tested this hypothesis by the application of the AgNOR staining method in our forensic post-mortem material. We aimed at both basic research on the neurobiology of suicide and the evaluation of possible diagnostic usefulness of the method in the differentiation between suicidal and non-suicidal death.

\section{Materials and methods}

\section{Human brain tissue}

Brainstems of suicide victims with unknown psychiatric comorbidity (typical for most of the suicide cases autopsied in our Department of Forensic Medicine) and sudden death controls were obtained during routine forensic autopsies in accordance with existing EU law regulations. The study has been approved by the local ethics committee of the Medical University of Gdańsk and performed in accordance with the ethical standards laid down in the Declaration of Helsinki of 1989.

Detailed diagnostic, demographic and toxicological data together with raw data of AgNOR measurements are presented in Supplementary Table. Violent suicide methods prevailed in the suicide cohort (23 out of 27 ), which are representative for our autopsy material. All brains were free of gross neuropathology suggestive of vascular, traumatic, inflammatory, neoplastic and neurodegenerative processes. A toxicology screening on blood and urine for ethanol was performed at each autopsy. The majority of investigated cases (17 suicide victims and 28 controls, see Supplementary Table) revealed the blood alcohol concentration (BAC) below the limit of quantification (LOQ), i.e. $<0.2 \mathrm{~g} / 1$ according to internationally accepted analytical guidelines. Other substances of abuse, antidepressant and antipsychotic drugs, as well as their metabolites were investigated when an intoxication was suggested by the scene inspection and/ or other available information sources prior to the autopsy, i.e. in three cases. These cases together with a helium inhalation victim constituted the non-violent suicide subgroup (see Supplementary Table).

Brainstems were isolated from the brains and fixed in toto in $10 \%$ phosphate-buffered formaldehyde for 1 week. After being fixated, tissue blocks containing the entire DRN were isolated from the brainstems and embedded in paraffin. Subsequently, serial 5- $\mu \mathrm{m}$-thick transverse sections were cut along the entire rostrocaudal axis of the DRN. Every 200th section was mounted and stained for AgNOR.

\section{AgNOR staining}

Silver staining was carried out as previously described [24]. Briefly, 5- $\mu \mathrm{m}$ paraffin sections were dewaxed and rehydrated through graded alcohols. The silver staining was freshly prepared by dissolving $2 \mathrm{~g} / \mathrm{dl}$ gelatin in $1 \mathrm{ml} /$ $\mathrm{dl}$ aqueous silver nitrate solution at a 1:2 ratio. The sections were incubated with this solution in a dark moist chamber at room temperature for $45 \mathrm{~min}$ and subsequently washed with deionised water. Following this protocol, the AgNOR area-containing AgNORs (that are clustered, undistinguishable from each other) and representing the nucleolus-appears as an intranuclear, clearly delineated black or dark brown small spot, and the nuclear border is clearly visible in the majority of large DRN neurons (Fig. 1), which are most probably serotonergic output neurons [48]. Glia cells were distinguished from neurons according to the established cytomorphological criteria [49]. 


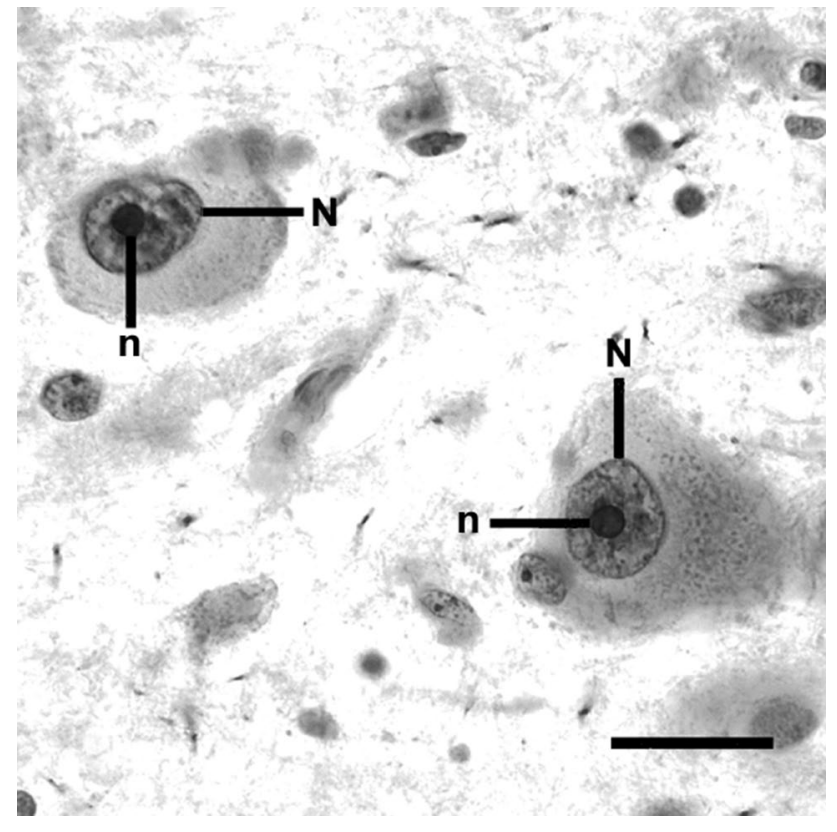

Fig. 1 After AgNOR staining, the borders of AgNOR areas (representing nucleoli) (n) are clearly visible within nuclei (N) of DRN neurons (control case, interfascicular subnucleus, scale bar $20 \mu \mathrm{m}$ ). The differences in AgNOR parameters were beyond qualitative evaluation, and they could only be captured by means of quantitative measurements

\section{Quantification}

In each of the DRN subnuclei (ventral, ventrolateral, dorsal, interfascicular and caudal [48]), AgNOR parameters were determined in 40 neurons with clearly visible borders of the nucleus and AgNOR areas (Fig. 1), which were selected throughout the available AgNOR-stained sections, i.e. in seven sections for a case, on average. Thus, the AgNOR parameters of 200 DRN neurons were investigated in each case. The number of investigated neurons was established arbitrarily in accordance with the guidelines on quantitative evaluation and diagnostic and research studies employing the AgNOR method. This method does not require an estimation of the number of cells and/or nuclei [24]. The neurons were sampled using a $400 \times$ magnification. The AgNOR areas (composed of clustered AgNORs and representing the nucleoli), their number and the nuclear area within a single-sampled neuron were determined using a light microscope attached to a computer image analysis system (cellSens $^{\circledR}$, Olympus, Japan). In this system, each of the neurons sampled by $400 \times$ magnification was visualised digitally and focused, and the sharpest and longest profiles of the nucleus and AgNOR areas were traced by the mouse cursor on the screen. As a result, the numerical values of AgNOR and the nuclear areas and the numbers of
AgNOR areas were calculated automatically. Subsequently, the AgNOR ratio (relative AgNOR area) was derived by dividing the total AgNOR area by the nuclear area, taking into account all the AgNOR areas present per neuronal nucleus. This procedure was performed separately for each of the sampled neurons. The sampled measures were averaged to derive a single set of values for each DRN subnucleus, for the rostral and caudal subdivisions of the DRN and for the entire DRN as a single anatomical structure in each of the investigated cases.

\section{Data analysis}

Statistical analyses were performed with the data analysis software system STATISTICA version 10 (StatSoft ${ }^{\circledR}$, Inc. 2011, www.statsoft.com). As normal distribution was not given for all analysed AgNOR parameters, nonparametric statistical procedures were used. Unadjusted two-way comparisons with the Mann-Whitney $U$ test were carried out to detect between-group differences.

The $\chi^{2}$ test and the $U$ test were used to detect the possible differences between the study groups with respect to sex, age, season of the year (month of death in spring/summer vs. autumn/winter), brain weight, post-mortem delay and BAC (whose values below LOQ were accounted null values in statistical analysis). All statistical tests were two tailed.

Spearman correlation coefficients were calculated to determine the impact of numerical variables which might confound the dependent variables.

Generally, $P$ values of $<0.05$ were accepted as statistically significant.

STATISTICA Automated Neuronal Networks (SANN) module containing receiver operating characteristic (ROC) procedure was applied for the evaluation of potential diagnostic value of the method, i.e. its accuracy (represented by the area under ROC curve), sensitivity and specificity.

\section{Results}

\section{Qualitative analysis of the AgNOR staining}

After AgNOR staining of the DRN neurons, borders of the AgNOR area (containing AgNORs that were clustered together and indistinguishable from each other) were clearly visible (Fig. 1) in line with the staining patterns in DRN neurons presented previously [24]. Most of the neurons contained one AgNOR area (representing the nucleolus in this staining method). Two or more AgNOR areas were observed very rarely, which explains why the AgNOR number was near 1 . 


\section{Quantitative analysis of the AgNOR staining}

The differences in AgNOR parameters were beyond qualitative evaluation, and they could only be captured by means of quantitative measurements.

The statistical analysis revealed highly significant differences by means of the cumulative analysis of all DRN subnuclei. Both the AgNOR area and the relative AgNOR area were decreased in suicide victims compared to controls (Table 1). No significant differences existed in any of the AgNOR parameters between violent $(n=23)$ and non-violent $(n=4)$ suicide victims. As revealed by the ROC curve for the AgNOR area, the method accuracy (represented by the area under ROC curve, AUC) is $83 \%$; its sensitivity according to the suicide diagnosis is $67 \%$, whereas the specificity of suicide exclusion (i.e. the diagnosis of nonsuicidal case) is $90 \%$. The respective values for the relative AgNOR area are: $85 \%$ (AUC), $78 \%$ (sensitivity) and $90 \%$ (specificity), and for both parameters when tested simultaneously they are: $89 \%$ (AUC), $85 \%$ (sensitivity) and $87 \%$ (specificity).

\section{Confounders}

Variables which could influence the AgNOR parameters in the DRN neurons, such as post-mortem interval (PMI), sex, age at death, season of the year (month of death in

Table 1 Presentation of significant diagnostic group differences regarding the evaluation of rDNA transcriptional activity in dorsal raphe nucleus neurons by the AgNOR staining (for the detailed values of parameters see Supplementary Table 1)

\begin{tabular}{lll}
\hline Parameter and group & $\begin{array}{l}\text { Parameter values } \\
\text { Median }(q 1, q 3, n)\end{array}$ & $\begin{array}{l}U \text { test } P \\
\text { S/C }\end{array}$ \\
\hline Nuclear area in $\mu \mathrm{m}^{2}$ & $\mathrm{~ns}$ \\
$\mathrm{~S}$ & $117.425(105.715,127.415$, & \\
& $27)$ & \\
$\mathrm{C}$ & $113.619(101.426,127.506$, & \\
& $30)$ & 0.000007 \\
AgNOR area in $\mu \mathrm{m}^{2}$ per & & \\
nucleus & $10.201(9.349,11.552,27)$ & \\
S & $12.315(11.443,13.178,30)$ & \\
C & \multicolumn{2}{c}{ ns } \\
Number of AgNORs per & $1.000(1.000,1.019,27)$ & \\
nucleus & $1.000(1.000,1.012,30)$ & \\
S & & 0.000002 \\
C & $0.086(0.081,0.092,27)$ & \\
Relative AgNOR area & $0.102(0.099,0.113,30)$ & \\
S &
\end{tabular}

$S$ suicide victims, $C$ controls, $q 1$ and $q 3$ quartile 1 and $3, n$ number of cases, $U$ test $P U$ test $P$ values, $n s$ non-significant spring/summer vs. autumn/winter) and brain weight were not associated with the values of the AgNOR parameters in the compared groups. No significant differences in these variables between suicides and controls were revealed. As the PMI is a very important confounder in post-mortem research, the hypothetical influence of this factor was excluded by an additional analysis of data. The cases with longest PMI (i.e. $\geq 70$ h, 6 cases in suicidal and 3 in control group, see Supplementary Table) were separated, and AgNOR parameters were compared between them and remaining cases in respective groups, which revealed nonsignificant $U$ test $P$ values. Moreover, intergroup comparisons were performed after exclusion of these cases, which supported the highly significant differences between suicidal and control groups in both the AgNOR area ( $U$ test $P$ value 0.000046 ) and the relative AgNOR area ( $U$ test $P$ value 0.000007 ; for a comparison see Table 2).

Although males unequivocally prevailed in suicidal versus control group ( $\chi^{2}$ test $P$ value 0.0002 , Table 2 ), no intragroup differences related to sex were found in any of AgNOR parameters, among them the AgNOR area and the relative AgNOR area (non-significant $U$ test $P$ values).

\section{Discussion}

Our study revealed a significantly decreased AgNOR area in DRN neurons suggestive of their decreased rDNA transcriptional activity in suicide victims versus controls. The observed effect was not confounded by other variables, among them post-mortem interval. The significance was shown in the cumulative analysis of all DRN subnuclei. This phenomenon could be related to the characteristic of DRN connections with target structures which overlap [57] in spite of the accentuated distinctiveness [50, 51].

The results are in line with our previously published findings, which suggested a decreased rDNA transcription in DRN neurons specific to depressed suicide completers (from both major depressive disorder and bipolar disorder diagnostic groups of affective disorders) compared to nonsuicidal depressed patients from these diagnostic groups [24]. Our recent findings in schizophrenia suggest a similar effect in suicidal compared to non-suicidal patients [52]. Therefore, our both previous and present results may suggest that the decreased rDNA transcription in DRN neurons is accentuated in suicide regardless of psychiatric comorbidity. In this way, they correspond also with the well-established view on serotonergic hypofunction as a diagnose-overreaching neurobiological phenomenon symptomatic of suicidal behaviour [1, 2, 4].

Regardless of the high statistical significance of our results ( $U$ test $P<0.00001$ ), both the AgNOR area and the AgNOR ratio values overlapped between the suicide and 
Table 2 Summarised data on the confounding variables analysis between suicide victims $(n=27)$ and control subjects $(n=30)$

\begin{tabular}{|c|c|c|c|c|c|}
\hline & & Sex & Age (year) & PMI (h) & $\mathrm{BAC}(\mathrm{g} / \mathrm{l})$ \\
\hline \multicolumn{6}{|l|}{ Intergroup comparisons } \\
\hline \multicolumn{2}{|c|}{ Suicide victims: ratio/median $(q, q 3)$} & $23 \mathrm{~m} / 4 \mathrm{f}$ & $43(28,53)$ & $24(24,48)$ & $0.0(0.0,2.1)$ \\
\hline \multicolumn{2}{|c|}{ Controls: ratio/median $(q 1, q 3)$} & $11 \mathrm{~m} / 19 \mathrm{f}$ & $48(39,61)$ & $24(24,48)$ & $0.0(0.0,0.0)$ \\
\hline \multicolumn{6}{|c|}{ Statistics (suicide victims versus Controls) } \\
\hline \multicolumn{2}{|l|}{ Test } & $\chi^{2}$ test & $U$ & $U$ & $U$ \\
\hline \multicolumn{2}{|l|}{ Characteristic value } & $\chi^{2}=13.90$ & $Z=1.886$ & $Z=-0.280$ & $Z=1.846$ \\
\hline \multicolumn{2}{|l|}{$P$ value } & 0.0002 & 0.059 & 0.780 & 0.065 \\
\hline \multicolumn{2}{|l|}{ AgNOR parameters } & & ge & PMI & BAC \\
\hline \multicolumn{6}{|c|}{$\begin{array}{l}\text { Correlation analysis between numerical confounding variables listed above and AgNOR parameters } \\
\text { revealing significant intergroup differences }\end{array}$} \\
\hline \multirow[t]{2}{*}{ AgNOR area } & $\mathrm{S}$ & $r / P$ & $0.16 / 0.42$ & $-0.05 / 0.80$ & $0.06 / 0.77$ \\
\hline & $\mathrm{C}$ & $r / P$ & $0.11 / 0.57$ & $-0.20 / 0.28$ & $0.18 / 0.33$ \\
\hline \multirow[t]{2}{*}{ Relative AgNOR area } & $\mathrm{S}$ & $r / P$ & $-0.14 / 0.47$ & $0.08 / 0.70$ & $0.28 / 0.16$ \\
\hline & $\mathrm{C}$ & $r / P$ & $0.09 / 0.62$ & $-0.04 / 0.85$ & $-0.01 / 0.97$ \\
\hline
\end{tabular}

$f$ female, $m$ male, $q 1$ and $q 3$ quartile 1 and 3, $P M I$ post-mortem interval, $B A C$ blood alcohol concentration, $S$ suicide victims, $C$ controls, $r$ correlation coefficient and $P P$ value of the Spearman's correlation, $P M I$ post-mortem interval, $B A C$ blood alcohol concentration non-suicide cohorts. Nevertheless, the area under ROC curve higher than $80 \%$ with similar sensitivity and specificity values suggests a diagnostic value of present AgNOR technique [53]. However, the confirmation of diagnostic relevance of the method needs further study of more numerous cohorts.

The rDNA transcription corresponds with the growth of both neuronal processes and neuronal body [45]. Therefore, our results are concurrent with those previous neuropathological studies, where a decrease in serotonergic axonal endings in the PFC [54-56] and the diminished neuronal body size in the DRN [26] were found in suicide victims.

On the other hand, the undisturbed or augmented expression of the key enzyme in serotonin synthesis, tryptophan hydroxylase (TPH), in DRN neurons in suicide was reported [16-18, 20, 22, 23, 28] (for a review see: [4]), which corresponds with the increased serotonin level found in DRN homogenates in suicide victims [57]. The production of neurotoxic metabolites subsequent to the increased intracellular serotonin concentration may damage the DNA of DRN neurons [58], which constitutes a potent inhibitor of rDNA transcription [59]. Therefore, one consequence of the increased TPH and subsequently augmented serotonin level in DRN neurons may be their decreased rRNA synthesis followed by deteriorated arborisation of serotonergic axons [60] in PFC regions.

The interpretation of our current results is not unequivocal due to the complicated nature of DRN activity regulation. The observed effect may be related to disturbances in 5HT2A receptor (5HT2AR) in limbic PFC areas, which provide the most afferents to the DRN $[8,61]$. The up-regulation of 5HT2ARs in the limbic PFC was observed in suicide [62] (for reviews see: [29, 63, 64]). In experimental models, the hyperfunction of these receptors on pyramidal neurons provides their increased output with subsequent inhibition of DRN neurons [65, 66], which may result in the attenuated rDNA transcription observed in our suicidal cohort.

On the other hand, experimental research on animal models suggests a sophisticated interaction between distal afferents and DRN neurons with an involvement of local circuits [65-71]. These local circuits may be dysregulated in suicide and thus contribute to the observed effect. The increased expression of presynaptic 5-HT1A auto-inhibitory receptors in the DRN in suicide may constitute one of the important local factors [72, 73]. The regionally disturbed function of corticotropin-releasing hormone (CRH) could also contribute to the decreased rDNA transcription in DRN neurons in suicide [15] (for reviews on CRH function in the DRN see: $[70,74])$.

The above-referenced findings point to a partially diminished protein synthesis as a consequence of the suggested rDNA activity decrease in the DRN in suicide. However, in a view of cited studies, the deteriorated rDNA activity in DRN neurons might play a fundamental role in the decrease of serotonergic terminals in the PFC. This abnormality provides a morphological substrate for the disturbed serotonergic neurotransmission in the PFC with profound consequences for the behavioural regulation. Therefore, the decreased rDNA activity with subsequently diminished plasticity of DRN neurons may constitute one of the key factors in the serotonergic dysfunction in suicide. 


\section{Limitations}

The present study has certain limitations that have to be considered: (1) A relatively small number of cases have been analysed, especially for the evaluation of potential diagnostic value of the method; therefore, results have to be confirmed in a larger sample. (2) The psychiatric diagnoses (also according to substance use disorders) and the data on possible psychotropic medication preceding death were not available. The levels of psychotropic drugs were established only in three suicide victims where medication overdose constituted a cause of death. However, our current study did not aim at the relation between suicide and other mental disorders, and our previous studies did not suggest that the decreased AgNOR area in DRN neurons may be related to the medication in the last three months of life [24]. (3) The application of paraffin-embedded tissue is a limitation of our method compared to frozen brain samples, which would allow the application of a wider set of approaches. (4) Although serotonergic neurons comprise about $70 \%$ of DRN neurons [7] and nearly all the large cells in this nucleus are serotonergic [5, 48], we could not determine the type of selected neurons by AgNOR staining. Since AgNOR areas correspond almost $100 \%$ to the nucleoli in DRN neurons, immunohistochemistry for tryptophan hydroxylase with a Nissl counterstain could bring to light, whether the cells with reduced AgNOR areas are really serotonergic. Furthermore, confocal immunofluorescence microscopy using antibodies against nucleolin and tryptophan hydroxylase could be another approach to resolve this issue.

\section{Conclusion}

In summary, our results suggest decreased rDNA transcription in DRN neurons in suicide as a presumable consequence of disturbed inputs to the DRN and/or their local transformation. The present method could probably aid forensic differentiation diagnostics between suicidal and non-suicidal death in cases where traditional methods do not solve this problem. However, the further research is warranted to appropriately evaluate this issue.

Acknowledgments The research was supported by the Polish Ministry of Science and Higher Education. The authors would like to thank J. Pracka for her excellent technical assistance.

\section{Compliance with ethical standards}

Conflict of interest On behalf of all authors, the corresponding author states that there is no conflict of interest.
Open Access This article is distributed under the terms of the Creative Commons Attribution 4.0 International License (http://creativecommons.org/licenses/by/4.0/), which permits unrestricted use, distribution, and reproduction in any medium, provided you give appropriate credit to the original author(s) and the source, provide a link to the Creative Commons license, and indicate if changes were made.

\section{References}

1. Ernst C, Mechawar N, Turecki G (2009) Suicide neurobiology. Prog Neurobiol 89:315-333

2. Mann JJ (2013) The serotonergic system in mood disorders and suicidal behaviour. Philos Trans R Soc Lond B Biol Sci 368:20120537. doi:10.1098/rstb.2012.0537

3. American Psychiatric Association (2013) Diagnostic and statistical manual of mental disorders, 5th edn. American Psychiatric Publishing, Arlington

4. Bach H, Arango V (2012) Neuroanatomy of serotonergic abnormalities in suicide. In: Dwivedi Y (ed) The neurobiological basis of suicide. CRC Press, Taylor \& Francis Group, New York, pp $11-27$

5. Jacobs BL, Azmitia EC (1992) Structure and function of the brain serotonin system. Physiol Rev 72:165-229

6. Van Bockstaele EJ, Biswas A, Pickel VM (1993) Topography of serotonin neurons in the dorsal raphe nucleus that send axon collaterals to the rat prefrontal cortex and nucleus accumbens. Brain Res 624:188-198

7. Wilson MA, Molliver ME (1991) The organization of serotonergic projections to cerebral cortex in primates: retrograde transport studies. Neuroscience 44:555-570

8. Peyron C, Petit JM, Rampon C et al (1998) Forebrain afferents to the rat dorsal raphe nucleus demonstrated by retrograde and anterograde tracing methods. Neuroscience 82:443-468

9. Jankowski MP, Sesack SR (2004) Prefrontal cortical projections to the rat dorsal raphe nucleus: ultrastructural features and associations with serotonin and gamma-aminobutyric acid neurons. J Comp Neurol 468:518-529

10. Andrade R, Haj-Dahmane S (2013) Serotonin neuron diversity in the dorsal raphe. ACS Chem Neurosci 4:22-25

11. Mahar I, Bambico FR, Mechawar N et al (2014) Stress, serotonin, and hippocampal neurogenesis in relation to depression and antidepressant effects. Neuroci Biobehav Rev 38:173-192

12. Marek GJ (2007) Serotonin and dopamine interactions in rodents and primates: implications for psychosis and antipsychotic drug development. Int Rev Neurobiol 78:165-192

13. Meltzer HY, Massey BW (2011) The role of serotonin receptors in the action of atypical antipsychotic drugs. Curr Opin Pharmacol 11:59-67

14. Arango V, Underwood MD, Boldrini M et al (2001) Serotonin $1 \mathrm{~A}$ receptors, serotonin transporter binding and serotonin transporter mRNA expression in the brainstem of depressed suicide victims. Neuropsychopharmacology 25:892-903

15. Austin MC, Janosky JE, Murphy HA (2003) Increased corticotropin-releasing hormone immunoreactivity in monoamine-containing pontine nuclei of depressed suicide men. Mol Psychiatry 8:324-332

16. Bach-Mizrachi H, Underwood MD, Kassir SA et al (2006) Neuronal tryptophan hydroxylase mRNA expression in human dorsal and median raphe nuclei: major depression and suicide. Neuropsychopharmacology 31:814-824

17. Bach-Mizrachi H, Underwood MD, Tin A et al (2008) Elevated expression of tryptophan hydroxylase- 2 mRNA at the neuronal 
level in the dorsal and median raphe nuclei of depressed suicides. Mol Psychiatry 13:507-513

18. Bielau H, Mawrin C, Krell D et al (2005) Differences in activation of the dorsal raphe nucleus depending on performance of suicide. Brain Res 1039:43-52

19. Bligh-Glover W, Kolli TN, Shapiro-Kulnane L et al (2000) The serotonin transporter in the midbrain of suicide victims with major depression. Biol Psychiatry 47:1015-1024

20. Boldrini M, Underwood MD, Mann JJ et al (2005) More tryptophan hydroxylase in the brainstem dorsal raphe nucleus in depressed suicides. Brain Res 1041:19-28

21. Boldrini M, Underwood MD, Mann JJ et al (2008) Serotonin$1 \mathrm{~A}$ autoreceptor binding in the dorsal raphe nucleus of depressed suicides. J Psychiatr Res 42:433-442

22. Bonkale WL, Murdock S, Janosky JE et al (2004) Normal levels of tryptophan hydroxylase immunoreactivity in the dorsal raphe of depressed suicide victims. J Neurochem 88:958-964

23. Bonkale WL, Turecki G, Austin MC (2006) Increased tryptophan hydroxylase immunoreactivity in the dorsal raphe nucleus of alcohol-dependent, depressed suicide subjects is restricted to the dorsal subnucleus. Synapse 60:81-85

24. Gos T, Krell D, Brisch R et al (2008) Demonstration of decreased activity of dorsal raphe nucleus neurons in depressed suicidal patients by the AgNOR staining method. J Affect Disord 111:251-260

25. Lloyd KG, Farley IJ, Deck JHN et al (1974) Serotonin and 5-hydroxyindoleacetic acid in discrete areas of the brainstem of suicide victims and control patients. Adv Biochem Psychopharmacol 11:387-397

26. Matthews PR, Harrison PJ (2012) A morphometric, immunohistochemical, and in situ hybridization study of the dorsal raphe nucleus in major depression, bipolar disorder, schizophrenia, and suicide. J Affect Disord 137:125-134

27. Stockmeier CA, Shapiro LA, Dilley GE et al (1998) Increase in serotonin-1A autoreceptors in the midbrain of suicide victims with major depression-postmortem evidence for decreased serotonin activity. J Neurosci 18:7394-7401

28. Underwood MD, Khaibulina AA, Ellis SP et al (1999) Morphometry of the dorsal raphe nucleus serotonergic neurons in suicide victims. Biol Psychiatry 46:473-783

29. Stockmeier CA (2003) Involvement of serotonin in depression: evidence from postmortem and imaging studies of serotonin receptors and the serotonin transporter. J Psychiatr Res 37:357-373

30. Mennel HD, Müller I (1994) Morphometric investigation on nuclear and nucleolar arrangement and AgNOR content in the rat hippocampus under normal and ischemic conditions. Exp Toxicol Pathol 46:491-501

31. Derenzini M (2000) The AgNORs. Micron 31:117-120

32. Garcia-Moreno LM, Cimadevilla JM, Gonzalez-Pardo H et al (1997) NOR activity in hippocampal areas during the postnatal development and ageing. Mech Ageing Dev 97:173-181

33. Gos T, Krell D, Brisch R et al (2007) The changes of AgNOR parameters of anterior cingulate pyramidal neurons are regionspecific in suicidal and non-suicidal depressive patients. World J Biol Psychiatry 8:245-255

34. Gos T, Krell D, Bielau H et al (2009) Demonstration of disturbed activity of orbitofrontal pyramidal neurons in depressed patients by the AgNOR staining method. J Affect Disord 118:131-138

35. Gos T, Krell D, Bielau H et al (2009) Demonstration of disturbed activity of external globus pallidus projecting neurons in depressed patients by the AgNOR staining method. J Affect Disord 119:149-155

36. Gos T, Krell D, Bielau H et al (2010) Demonstration of disturbed activity of the lateral amygdaloid nucleus projection neurons in depressed patients by the AgNOR staining method. J Affect Disord 126:402-410

37. Gos T, Steiner J, Krell D et al (2013) Ribosomal DNA transcription in the anterior cingulate cortex is decreased in unipolar but not bipolar depression. Psychiatry Res 210:338-345

38. Hayashida M, Miyaoka T, Tsuchie K et al (2009) Hyperbilirubinemia-related behavioral and neuropathological changes in rats: a possible schizophrenia animal model. Prog Neuropsychopharmacol Biol Psychiatry 33:581-588

39. Ploton D, Menager M, Jeannesson $P$ et al (1986) Improvement in the staining and in the visualization of the argyrophilic proteins of the nucleolar organiser region at the optical level. Histochem $\mathrm{J}$ 18:5-14

40. Ploton D, Visseaux-Coletto B, Canellas JC et al (1992) Semiautomatic quantification of silver-stained nucleolar organiser regions in tissue sections and cellular smears. Anal Quant Cytol Histol 14:14-23

41. Ploton D (1994) Structure and molecular organization of the nucleolus. Zentralbl Pathol 140:3-6

42. Rüschoff J, Elsässer HP, Adler G (1995) Correlation of nucleolar organizer regions with secretory and regenerative process in experimental cerulein-induced pancreatitis in the rat. Pancreas 11:154-159

43. Raska I, Shaw PJ, Cmarko D (2006) New insights into nucleolar architecture and activity. Int Rev Cytol 255:177-235

44. Sirri V, Urcuqui-Inchima S, Roussel P et al (2008) Nucleolus: the fascinating nuclear body. Histochem Cell Biol 129:13-31

45. Gomes C, Smith SC, Youssef MN et al (2011) RNA polymerase 1-driven transcription as a mediator of BDNF-induced neurite outgrowth. J Biol Chem 286:4357-4363

46. McGowan PO, Szyf M (2010) The epigenetics of social adversity in early life: implications for mental health outcomes. Neurobiol Dis 39:66-72

47. Gos T, Krell D, Brisch R et al (2007) The changes in AgNOR parameters of dorsal raphe nucleus neurons are related to suicide. Leg Med (Tokyo) 9:251-257

48. Baker KG, Halliday GM, Törk I (1990) Cytoarchitecture of the human dorsal raphe nucleus. J Comp Neurol 301:147-161

49. Polak M, Haymaker W, Johnson JE et al (1982) Neuroglia and their reactions. In: Haymaker W, Adams RD (eds) Histology and histopathology of nervous system. Thomas Publishing, Springfield, Charles C, pp 363-480

50. Vasudeva RK, Lin RCS, Simpson KL et al (2011) Functional organization of the dorsal raphe efferent system with special consideration of nitrergic cell groups. J Chem Neuroanat 41:281-293

51. Hale MW, Shekhar A, Lowry CA (2012) Stress-related serotonergic system: implications for symptomology of anxiety and affective disorders. Cell Mol Neurobiol 32:695-708

52. Krzyżanowska M, Steiner J, Brisch R et al (2015) Ribosomal DNA transcription in the dorsal raphe nucleus is increased in residual but not in paranoid schizophrenia. Eur Arch Psychiatry Clin Neurosci 265:117-126

53. Perlis RH (2011) Translating biomarkers to clinical practice. Mol Psychiatry 16:1076-1087

54. Arango V, Underwood MD, Mann JJ (2002) Serotonin brain circuits involved in major depression and suicide. Prog Brain Res 136:443-453

55. Austin MC, Whitehead RE, Edgar CL et al (2002) Localized decrease in serotonin transporter-immunoreactive axons in the prefrontal cortex of depressed subjects committing suicide. Neuroscience 114:807-815

56. Underwood MD, Kassir SA, Bakalian MJ et al (2012) Neuron density and serotonin receptor binding in prefrontal cortex in suicide. Int J Neuropsychopharmacol 15:435-447 
57. Bach H, Huang YY, Underwood MD et al (2014) Elevated serotonin and 5-HIAA in the brainstem and lower serotonin turnover in the prefrontal cortex of suicides. Synapse 68:127-130

58. Burke WJ, Park DH, Chung HD et al (1990) Evidence for decreased transport of tryptophan hydroxylase in Alzheimer's disease. Brain Res 537:83-87

59. Goodfellow SJ, Zomerdijk JC (2013) Basic mechanisms in RNA Polymerase I transcription of the ribosomal RNA genes. Subcell Biochem 61:211-236

60. Koert CE, Spencer GE, van Minnen J et al (2001) Functional implications of neurotransmitter expression during axonal regeneration: serotonin, but not peptides, auto-regulate axon growth of an identified central neuron. J Neurosci 21:5597-5606

61. Lee HS, Kim M-A, Valentino RJ et al (2003) Glutamatergic afferent projections to the dorsal raphe nucleus of the rat. Brain Res 963:57-71

62. Oquendo MA, Russo SA, Underwood MD et al (2006) Higher postmortem prefrontal 5-HT 2A receptor binding correlates with lifetime aggression in suicide. Biol Psychiatry 59:235-243

63. Savitz JB, Drevets WC (2013) Neuroreceptor imaging in depression. Neurobiol Dis 52:49-65

64. Meyer JH (2012) Neuroimaging high risk states for suicide. In: Dwivedi Y (ed) The neurobiological basis of suicide. Taylor \& Francis Group, New York, pp 159-194

65. Coplan JD, Gopinath S, Abdallah CG et al (2014) A neurobiological hypothesis of treatment-resistant depression-mechanisms for selective serotonin reuptake inhibitor non-efficacy. Front Behav Neurosci 8:169. doi:10.3389/fnbeh.2014.00189
66. Sharp T, Boothman L, Raley J et al (2007) Important messages in the 'post': recent discoveries in 5-HT neurone feedback control. Trends Pharmacol Sci 28:629-636

67. Artigas F (2013) Serotonin receptors involved in antidepressant effects. Pharmacol Ther 137:119-131

68. Celada P, Puig MV, Casanovas JM et al (2001) Control of dorsal raphe serotonergic neurons by the medial prefrontal cortex: involvement of serotonin-1A, GABAA, and glutamate receptors. J Neurosci 21:9917-9929

69. Soiza-Reilly M, Commons KG (2011) Glutamatergic drive of the dorsal raphe nucleus. J Chem Neuroanat 41:247-255

70. Valentino RJ, Lucki I, Van Bocksteale EJ (2010) Corticotropinreleasing factor in the dorsal raphe nucleus: linking stress coping and addiction. Brain Res 1314:29-37

71. Varga V, Székely AD, Csillaq A et al (2001) Evidence for a role of GABA interneurones in the cortical modulation of midbrain 5-hydroxytryptamine neurones. Neuroscience 106:783-792

72. Lemonde $S$, Turecki G, Bakish D et al (2003) Impaired repression at a 5-hydroxyamine $1 \mathrm{~A}$ receptor gene polymorphism associated with major depression and suicide. J Neurosci 23:8788-8799

73. Albert PR, Lemonde S (2004) 5-HT $\mathrm{HA}_{1 \mathrm{~A}}$ receptors, gene repression, and depression: guilt by association. Neuroscientist 10:575-593

74. Fox JH, Lowry CA (2013) Corticotropin-releasing factor-related peptides, serotonergic systems and emotional behavior. Front Neurosci 7:169. doi:10.3389/fnins.2013.00169 